\title{
Crew and Thermal Systems Strategic Communications Initiatives in Support of NASA's Strategic Goals
}

\author{
Heather L. Paul \\ Erika Guillory Lamberth \\ Mallory A. Jennings \\ NASA Johnson Space Center, Houston, Texas 77058
}

\begin{abstract}
NASA has defined strategic goals to invest in next-generation technologies and innovations, inspire students to become the future leaders of space exploration, and expand partnerships with industry and academia around the world. The Crew and Thermal Systems Division (CTSD) at the NASA Johnson Space Center actively supports these NASA initiatives. In July 2011, CTSD created a strategic communications team to communicate CTSD capabilities, technologies, and personnel to external technical audiences for business development and collaborative initiatives, and to students, educators, and the general public for education and public outreach efforts. This paper summarizes the CTSD Strategic Communications efforts and metrics through the first half of fiscal year 2012 with projections for end of fiscal year data.
\end{abstract}

